\title{
Autoclaved Brick from Volume-Stability-Modified Steel Slag and Low Silicon Tailings
}

\author{
Li Peng-guan ${ }^{1,2, a}$ and Zhao Feng-qing ${ }^{1,3, b}$ \\ ${ }^{1}$ Department of Chemical Engineering, Hebei University of Science \& Technology, Shijiazhuang \\ 050018 P.R. China \\ ${ }^{2}$ Hebei Research Center of Pharmaceutical and Chemical Engineering, Shijiazhuang, P.R. China \\ ${ }^{3}$ Hebei Engineering and Research Center of Solid Waste Utilization, Shijiazhuang, P.R. China \\ a564663554@qq.com, , zhaofq3366@126.com(corresponding author)
}

\begin{abstract}
Steel slag is a major industrial waste. Because of poor volume stability, its utilization was limited. We adopted polyphosphate modified steel slag and tailings to produce the autoclaved brick. The effects of various factors influencing the performance of brick were investigated, and the results were obtained: forming water $9 \%$, forming pressure $20 \mathrm{MPa}$, curing regime 4 (temperature rising, hr)-4(temperature holding at $180^{\circ} \mathrm{C}$, hr)-natural cooling (temperature dropping). With the content of modified steel slag in brick increased from $11 \%$ to $25 \%$, the content of cement reduced from $7 \%$ to $5 \%$, the compressive strength value increased from 11.6MPa to $22.1 \mathrm{MPa}$.
\end{abstract}

Keywords: Steel slag, Iron tailings, Volume stability, Autoclaved brick

\section{Introduction}

Large-scale industrial mining operations generate thousands of tons of waste rock and tailings, which not only pollute the air, soil and ground water, but also induce geological disaster. So far by now, there were more than five billion tons accumulated steel slag in China, most of them is still land filled [1,2]. It has caused extensive attention of state and local governments. Early in the 20th century, the developed countries begun to concern the utilization of steel slag. In some countries like United States, Germany and Japan, the utilization of steel slag was over $95 \%$, while only $30 \%$ was used in China [3].

Steel slag is a kind of waste residue generated from steel-making plant with temperature above $1400^{\circ} \mathrm{C}$. Its main mineral phases is similar to in chemical component to cement, which attribute steel slag the potential cementitious activity and make it possible to be applied in building materials [4]. Using steel slag totally or partly replace the cement, mixed with tailings and cement in a certain proportion, to produce the autoclaved bricks can not only protect the environment, but also reduce production cost. However, there is a certain amount of free calcium oxide and magnesium oxide in the steel slag, which will lead to volume expansion in construction and building material for a long time and cause bricks cracking [5].

In this paper, we first adopt the polyphosphate based slaking agent to treat steel slag. Then use the modified steel slag to replace cement partly in producing autoclaved brick 
with low silicon tailings. Thus the content in brick of steel slag is increased, cement reduced and thus realizing the high-added value use of steel slag.

\section{Materials and Methods}

\subsection{Raw Materials}

In the experiment, steel slag and tailings are both from Central Solid Waste utilization Ltd of Tangshan Zunhua city. The stability modifier of slag called VS-I is mainly a mixture of polyphosphate. The Chemical Composition of steel slag and tailings has shown in the Table 1.

TABLE 1 CHEMICAL CONSTITUENTS OF STEEL SLAG AND TAILING

\begin{tabular}{cccccccc}
\hline & $\mathrm{CaO}$ & $\mathrm{MgO}$ & $\mathrm{SiO}_{2}$ & $\mathrm{Fe}_{2} \mathrm{O}_{3}$ & $\mathrm{Al}_{2} \mathrm{O}_{3}$ & $\mathrm{f}-\mathrm{CaO}$ & Loss \\
\hline Steel slag & & & & & & & \\
{$[\%, w t]$} & 49.64 & 21.93 & 17.51 & 3.55 & 3.53 & 2.18 & 1.66 \\
\hline Tailings & & & & & & & \\
{$[\%, w t]$} & 12.80 & 23.54 & 45.34 & 3.83 & 3.65 & - & 4.36 \\
\hline
\end{tabular}

\subsection{Samples Forming and Curing}

Firstly add steel slag into the ball mill, grinding, mix with $1.5 \%$ of the VS-I (mass percentage of steel slag) and small amount of water, wet curing $4 \mathrm{~h}$ in normal temperature. Then mix the modified steel slag powder with cement, tailings and water. Then press forming into samples in size of $50 \times 50 \times 50 \mathrm{~mm}$. Autoclave the samples (blocks) in accordance with the appropriate curing regime.

\subsection{Performance Measurement and Analysis}

The mechanical strength values of the samples were tested according to JC239-2001. The volume stability (cracking or not) was observed with naked eye.

\section{Results and Discussion}

\subsection{Effect of Forming Water on Autoclaved Brick}

Mix modified steel slag, cement, and tailings at the mass ratio of 25:7:68, pressure forming at $20 \mathrm{MPa}$. And then transform the forming water under the curing regime 4(temperature rising, hr)-4(temperature holding at $180^{\circ} \mathrm{C}, \mathrm{hr}$ )-natural cooling (temperature dropping). Compressive strength of the blocks were tested and the result were shown in the Figure 1. 


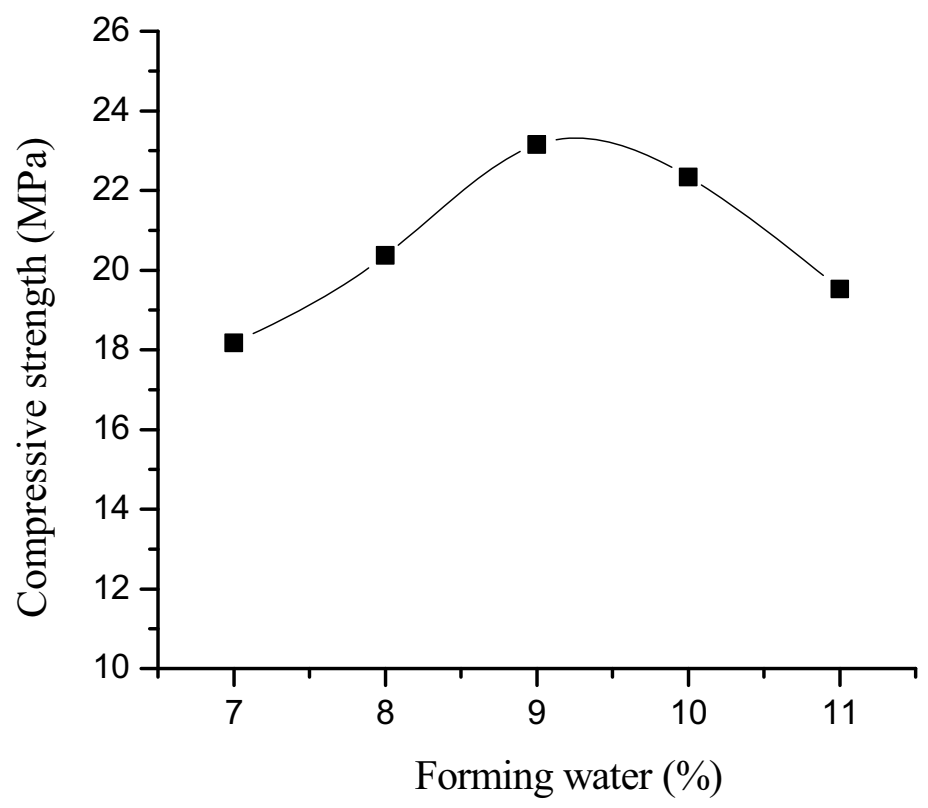

Fig.1 Effect of forming water on autoclaved brick

Figure 1 shows that with the increase of forming water, the compressive strength of blocks was increased at first and later decreased. The highest is $23.5 \mathrm{MPa}$ when the forming water is $9 \%$. When the forming water continues to increase, part of unnecessary moisture remain in the blocks. They gradually escape in the autoclave curing process, which cause porosity increases, density and compressive strength decline [6].

\subsection{Effect of Forming Pressure on Autoclaved Brick}

Mix modified steel slag, cement, and tailings at the mass ratio of 25:7:68 to prepare blocks with forming water $9 \%$. And then change the forming pressure under the curing regime 4(temperature rising, hr)-4(temperature holding at $180^{\circ} \mathrm{C}$, hr)-natural cooling (temperature dropping). Compressive strength of the blocks were tested and the result shown in the Figure 2. 


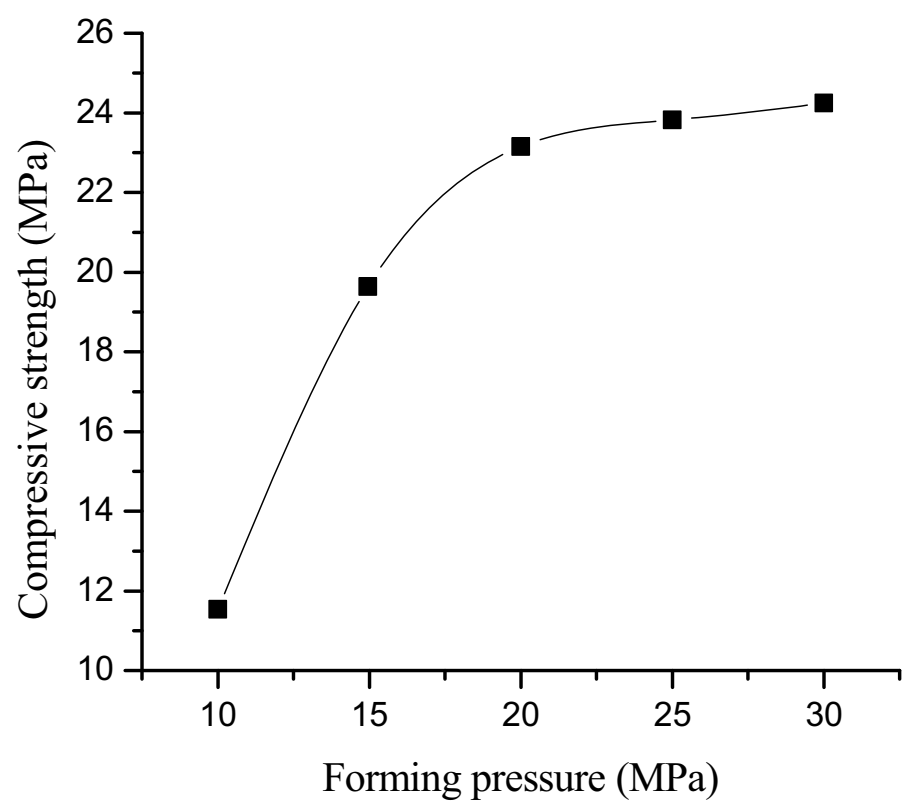

Fig.2 Effect of forming pressure on autoclaved brick

Figure 2 shows that when the forming pressure increase at 10 20MPa, the compressive strength rise significantly. When the forming pressure increased, the compressive strength increased. Two high pressure will cause the density of blocks too large with heavy quality and influence the application [7]. The optimum forming pressure is $20 \mathrm{MPa}$.

\subsection{Effect of Autoclave Temperature on Autoclaved Brick}

Mix modified steel slag, cement, and tailings at the mass ratio of 25:7:68 to prepare blocks with forming water $9 \%$, forming pressure $20 \mathrm{MPa}$. Change the autoclave temperature under the curing regime 4(temperature rising, hr)-4(temperature holding, hr)-natural cooling (temperature dropping). Compressive strength of the blocks were tested and the result shown in the Figure 3. When the autoclave temperature increase at the $100 \sim 180^{\circ} \mathrm{C}$, the compressive strength of blocks rise rapidly. When the autoclave temperature exceed $180^{\circ} \mathrm{C}$, the compressive strength of blocks rises slowly, and leveled off. The appropriate autoclaved temperature is thus $180^{\circ} \mathrm{C}$. 


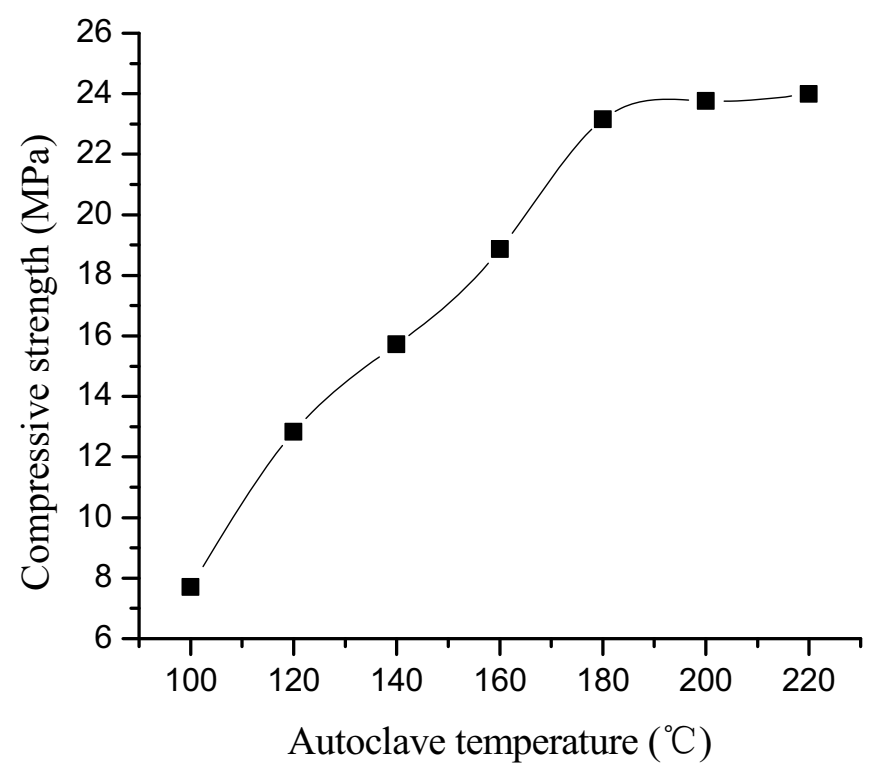

Fig.3 Effect of autoclave temperature on autoclaved brick

\subsection{Effect of Constant Temperature Time on Autoclaved Brick}

Mix modified steel slag, cement and tailings at the mass ratio of 25:7:68, and preparing blocks with forming water $9 \%$, forming pressure $20 \mathrm{MPa}$. And then changes constant autoclave time under the curing regime 4(temperature rising, hr)-(temperature holding at $180^{\circ} \mathrm{C}$ )-natural cooling (temperature dropping). Compressive strength of the blocks were tested and the result shown in the Figure 4. It is shown that the appropriate constant temperature time is $4 \mathrm{~h}$. 


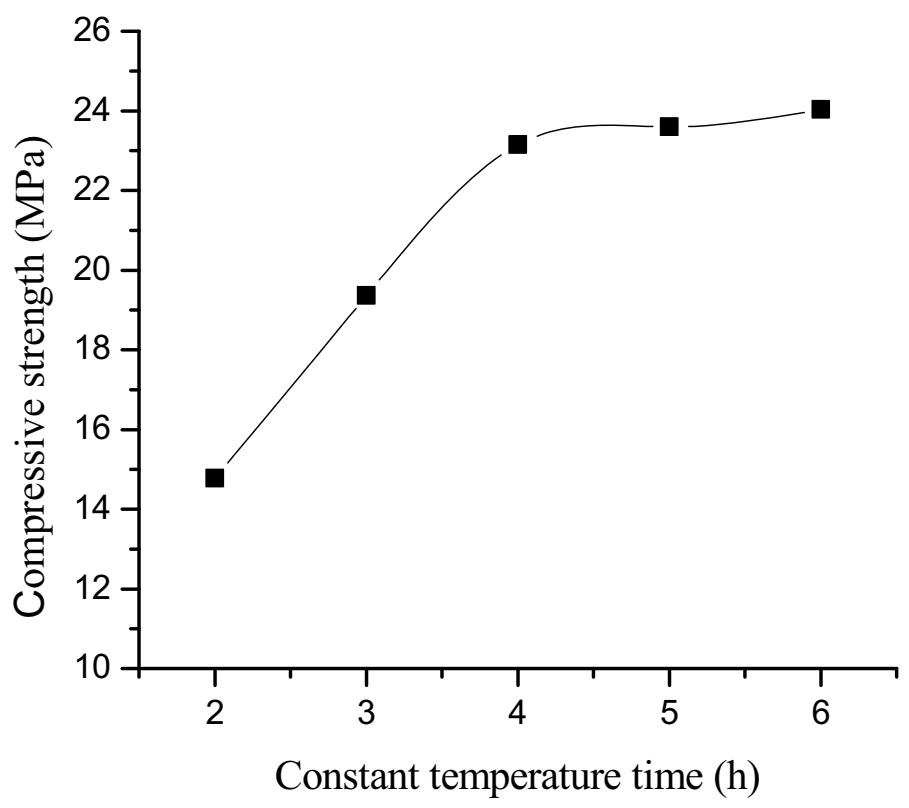

Fig.4 Effect of constant temperature time on autoclaved brick

\subsection{Effect of the Content of Modified Steel Slag on Autoclaved Brick}

According to the above results, the appropriate conditions were obtained: forming water $9 \%$, forming pressure $20 \mathrm{MPa}$, curing regime 4 (temperature rising, hr)-4 (temperature holding at $180^{\circ} \mathrm{C}, \mathrm{hr}$ )-natural cooling( temperature dropping). Under this condition, we increase the content of steel slag appropriately. Compressive strength of the blocks were tested and the result shown in the Table 2.

TABLE 2 EFFECT OF THE CONTENT OF MODIFIED STEEL SLAG ON

$$
\text { AUTOCLAVED BRICK }
$$

\begin{tabular}{ccccccc}
\hline \multirow{2}{*}{ Treatment } & $\begin{array}{c}\text { Forming } \\
\text { water }\end{array}$ & $\begin{array}{c}\text { Forming } \\
\text { pressure }\end{array}$ & Cement & Steel slag & $\begin{array}{c}\text { Volume } \\
\text { stability }\end{array}$ & $\begin{array}{c}\text { Compressiv } \\
\text { e strength }\end{array}$ \\
\hline $\begin{array}{c}\text { Grinding } \\
\text { non-modified }\end{array}$ & $9 \%$ & $20 \mathrm{MPa}$ & $7 \%$ & $12 \%$ & Crack & - \\
\hline & $9 \%$ & $20 \mathrm{MPa}$ & $7 \%$ & $10 \%$ & Intact & $12.2 \mathrm{MPa}$ \\
\cline { 2 - 7 } & $9 \%$ & $20 \mathrm{MPa}$ & $7 \%$ & $15 \%$ & Intact & $16.4 \mathrm{MPa}$ \\
\cline { 2 - 7 } Grinding \\
\cline { 2 - 7 } & $9 \%$ & $20 \mathrm{MPa}$ & $7 \%$ & $20 \%$ & Intact & $20.5 \mathrm{MPa}$ \\
\cline { 2 - 7 } & $9 \%$ & $20 \mathrm{MPa}$ & $7 \%$ & $25 \%$ & Intact & $23.1 \mathrm{MPa}$ \\
\cline { 2 - 7 } & $9 \%$ & $20 \mathrm{MPa}$ & $5 \%$ & $25 \%$ & Intact & $22.1 \mathrm{MPa}$ \\
\hline
\end{tabular}


Table 2 shows that when the content of steel slag is $25 \%$, the content of cement reduced to $5 \%$. Then the compressive strength of blocks can reach up to $22.1 \mathrm{MPa}$ and satisfy the MU20 grade requirements of JC239-2001.

\section{Conclusion}

Based on the steel slag modified by polyphosphates, the effects of forming water, forming pressure and curing regime influencing the performance of brick were investigated. The appropriate conditions were obtained: forming water $9 \%$, forming pressure $20 \mathrm{MPa}$, curing regime 4(temperature rising, hr)-4(temperature holding at $180{ }^{\circ} \mathrm{C}$,hr)-natural cooling( temperature dropping). The products satisfy JC239-2001MU20 grade requirements (Fly Ash Bricks), and the compressive strength of blocks reached up to $22.1 \mathrm{MPa}$.

Compared with the present technology, the content of steel slag increase from $11 \%$ (non-modified) to $25 \%$ (modified), the cement reduced from $7 \%$ to $5 \%$. The compressive strength improved obviously from $11.6 \mathrm{MPa}$ to $22.1 \mathrm{MPa}$. This work provides solid basis for treatment, disposal and utilization of steel slag and tailings.

\section{References}

1. P.G. Li, F.Q. Zhao, et al. Improving the volume stability of steel slag for construction and building materials, J. Advanced Materials Research. 936 (2014) 1399-1403.

2. F.Q. Zhao, J. Zhao, et al. Autoclaved brick from low silicon tailings, J. C. \& B. Materials. 23 (2009) 539-541.

3. Essia Belhadj, Cécile Diliberto, et al. Characterization and activation of basic oxygen furnace slag, J. Cement \& Concrete Composites. 34 (2012) 34-40.

4. P.G. Li, F.Q. Zhao. Autoclaved brick from steel slag and silicon tailings, J. Advanced Materials Research. 878 (2014) 194-198.

5. Zhang Zhi-guo, Li Peng-guan, et al. Pretreatment of steel slag for autoclaved brick, J. Brick-tile., 3 (2014) 3-5. (in Chinese)

6. H. Li, F.Q. Zhao, et al. Autoclaved brick from semi-dry desulfuration ash, J. Advanced Materials Research. 846 (2010) 217-218.

7. Zhao Feng-qing, Xiao Jin-yi, Chen Jian-bo. Investigation on factors influencing autoclaved brick from low silicon tailings, J. Non-Metal Mine. 5 (2007) 78-80. (in Chinese) 